\title{
Simplified Chinese Version of the International Prostate Symptom Score and the Benign Prostatic Hyperplasia Impact Index: Cross-Cultural Adaptation, Reliability, and Validity for Patients with Benign Prostatic Hyperplasia
}

\section{Rong-liang Dun}

Yueyang Hospital of Integrated Traditional Chinese and Western Medicine Hospital, Shanghai University of Traditional Chinese Medicine

Jian-min Mao

Shanghai Seventh People's Hospital

Chao Yu

Shanghai University of Traditional Chinese Medicine

\section{Qiang Zhang}

Yueyang Hospital of Integrated Traditional Chinese and Western Medicine Hospital, Shanghai University of Traditional Chinese Medicine

Xiao-hua Hu

Yueyang Hospital of Integrated Traditional Chinese and Western Medicine Hospital, Shanghai University of Traditional Chinese Medicine

\section{Wen-jing Zhu}

Yueyang Hospital of Integrated Traditional Chinese and Western Medicine Hospital, Shanghai University of Traditional Chinese Medicine

\section{Guang-chong Qi}

Yueyang Hospital of Integrated Traditional Chinese and Western Medicine Hospital, Shanghai University of Traditional Chinese Medicine

\section{Yu Peng ( $\Delta 776576020 @ q q . c o m)$}

Yueyang Hospital of Integrated Traditional Chinese and Western Medicine Hospital, Shanghai University of Traditional Chinese Medicine

\section{Research Article}

Keywords: Cross-cultural adaptation, Questionnaires, Psychometric, Benign prostatic hyperplasia, Quality of life 
Posted Date: December 30th, 2021

DOI: https://doi.org/10.21203/rs.3.rs-1209172/v1

License: (c) (i) This work is licensed under a Creative Commons Attribution 4.0 International License. Read Full License 


\section{Abstract}

Purpose: The aim of this study was to translate and cross-cultural adapt the international prostate symptom score (IPSS) and benign prostatic hyperplasia impact index (BII) into simplified Chinese for mainland Chinese patients with benign prostatic hyperplasia (BPH).

Methods: The original English IPSS and BII were translated into simplified Chinese versions, based on cross-cultural adaptation guidelines. Internal consistency was evaluated with Cronbach' a, then test-retest reliability with intraclass correlation coefficients (ICCs) in stable patients. The validity of these two adaptations was tested by the correlation between the IPSS, and BII with visual prostate symptom score (VPSS), and 36 items Short Form Health Survey (SF-36). The floor and ceiling effects were calculated by the proportion of participants who obtained the highest and lowest possible score.

Results: A total of 105 native Chinese-speaking patients with BPH were enrolled. Cronbach' a were over 0.75 for the simplified Chinese IPSS (IPSS 0.815; IPSS-symptom 0.782), and 0.709 for the simplified Chinese BII, indicating acceptable internal consistency. The ICCs for the test-retest reliability were over 0.75 (IPSS, $r=0.836$; IPSS-symptom, $r=0.801$; IPSS-quality of life, $r=0.794$; BII, $r=0.758$ ), indicating excellent test-retest reliability. There were very good positive correlations between IPSS and BII $(r=0.605)$, as well as VPSS ( $r=0.634)$, and very good or good negative correlations between IPSS-Qol and SF-36 physical functioning $(r=-0.621)$, and vitality $(r=-0.659)$, and between BII and SF-36 physical functioning $(r=-0.421)$. No floor or ceiling effect was detected in the simplified Chinese IPSS and BII.

Conclusions: This study indicates that the simplified Chinese IPSS and BII are reliable and valid measurement of the symptom and quality of life among Chinese patients with $\mathrm{BPH}$, which is likely to be widely used in this population.

\section{Introduction}

Benign prostatic hyperplasia (BPH) is a common condition in middle-aged and older men [1]. It typically develops after the age of 40 years, and its prevalence ranges from $>50 \%$ at 60 years, to as high as $\sim 90 \%$ at 85 years of age [2]. BPH patients suffer from lower urinary tract symptoms (LUTS) include obstructive (incomplete emptying, intermittent voiding, weak stream, straining) and irritative (frequent voiding, urgency, nocturia) urinary symptoms [3]. As the changes in sleep patterns, anxiety and embarrassment, altered mobility, changes in leisure, daily-living and sexual activities, patients with LUTS due to BPH experience a significant deterioration in quality of life (QoL) [4]. In addition, BPH can also lead to more serious complications, such as acute urinary retention, recurrent urinary tract infections, hematuria, bladder calculi, as well as renal dysfunction [3].

Patient report outcome measures usually in the form of questionnaire provide a method for the standardized collection of data from patients. The first version of the International Prostate Symptom Score (IPSS) was created in 1992 by the American Urological Association (AUA) for the assessment of the aging male with LUTS due to BPH, which was originally called AUA symptom index (AUA-SI) [5]. It 
originally consisted of 7 questions, lacking the QoL question, then the World Health Organization added the QoL question, and adopted the AUA-SI as the final IPSS [6]. The IPSS was considered to be an easy, self-administered questionnaire with application even in primary health care clinics. The AUA committee also developed the BPH Impact Index (BII) to assess the impact of BPH symptoms on patients' physical and mental health [7]. The BII is a self-administered questionnaire with 4 questions about urinary problems during the past month regarding physical discomfort, worry about health, how bothersome symptoms are, and whether the symptoms are interfering with doing usual activities.

The IPSS and BII had been found to be valid and reliable patient reported outcome measurement for patients with LUTS, or BPH in previous studies [8-10]. Both these two scales had been translated and adapted into other languages, such as Urdu, Arabic, Spanish, Japanese, and traditional Chinese-Hong Kong, or Mandarin in Malaysian, while a simplified Chinese version for mainland Chinese residents is not available [11-14]. The objectives of this study were to translate the IPSS and BII for simplified Chinese, and to assess the factor structure, internal consistency, test-retest reliability, validity, as well as floor and ceiling effects of the simplified Chinese IPSS and BII in mainland Chinese patients with LUTS due to BPH.

\section{Methods}

\section{Ethical considerations}

The full study protocol was approved by the Research Ethics Committee from Yueyang Hospital of integrated traditional Chinese and Western Medicine. Informed consent was obtained from all patients involved in the study with no amendments (No. 2016LCSY030).

\section{Cross-cultural adaptation and translation}

\section{Stage I: translation the IPSS, and BII into simplified Chinese language and synthesis}

The forward translation was conducted by two native bilingual Chinese-speaking translators independently ( $\mathrm{T} 1$ and $\mathrm{T} 2$ ), one was a urologist, and the other was a professional English translator, then the two translated versions (T1 and T2) were compared for any inconsistencies, and synthesized into T12. It was then back-translated into English by two independent native English-speaking professional translators (B1 and B2), who did not know the original English IPSS, and BII in advance. The translated versions (T1, T2, T1-2, B1 and B2) were compared with the original English version by all the translators and a bilingual expert committee, consisting of a senior English teacher, an urologist, and a cross-cultural translation expert. A pre-final simplified Chinese IPSS and BII was established by consensus from all the translators and the expert committee. 
After all, $31 \mathrm{BPH}$ patients with LUST who met the following inclusion criteria: (1) native simplified Chinese speakers; (2) men who were 45 years old or older, with LUTS due to BPH; and (3) had no reading difficulty in Chinese, were enrolled to complete the pre-final simplified Chinese IPSS, and BII. The patients finished the questionnaire, and they were asked if the items were clear and easy to understand. Suggestions and doubts were also collected from these patients. All the translators, and the expert committee discussed, and revised the pre-final simplified Chinese IPSS and BII according to these details as the final version.

\section{Stage II: test of the final version}

A booklet, covering the final simplified Chinese IPSS, BII, as well as the visual prostate symptom score (VPSS), 36 items Short Form Health Survey (SF-36), and Patients' Global Evaluation (PGE) was used in the study. Meanwhile, participant demographic information was also included, including age, disease duration, and so on.

\section{Patients}

The study involved native simplified Chinese-speaking men at least 45 years of age, with LUTS due to BPH who consecutively consulted in Yueyang Hospital of integrated traditional Chinese and Western Medicine, Shanghai Seventh People's Hospital, and Longhua Hospital, Shanghai University of Traditional Chinese Medicine.

The sample size of such a cross-cultural adaptation should meet two conditions; the sample size should be above 100, and over 7 times the number of items. The IPSS has eight items, and BII had 10 items, therefore, at least 100 patients needed to be enrolled [15].

\section{Instruments}

\section{International prostate symptom score}

IPSS evaluated a combination of voiding symptoms (IPSS-symptom) and QoL related to voiding (IPSSQoL). The IPSS-symptom allows the patient to choose 1 of 6 answers indicating increasing severity of the particular symptom. The answers are assigned points from 0 to 5 . The total score of IPSS-symptom ranges from 0 to 35 , higher scores indicating greater BPH symptom-related impact [6]. The IPSS-QoL is a six-point Likert scale, higher score indicating lower QoL impacted by BPH symptom.

\section{Benign prostatic hyperplasia impact index}


The BII measures physical discomfort, worry, bother, and interference with usual activities, then the physical discomfort, worry, and bother items have a four-point Likert scale; and the interference with usual activities item has a five-point Likert scale. The total score ranges from 0 to 13 , higher scores indicating greater BPH symptom-related impact [7].

\section{Visual Prostate Symptom Score}

VPSS is an alternative questionnaire used to avoid the aforementioned problems when using the IPSS. It can be used to assess urinary frequency during daytime and nighttime, the stream of urine, and the QoL by means of pictograms [16].

\section{The Short Form Health Survey (SF-36)}

The SF-36 is used to evaluate patients' QoL with eight dimensions, ranging from 0 (poor health) to 100 (good health) [17]. It was suggested that the simplified Chinese version of the SF-36 functioned in the general population of China quite similarly to the original American population tested [18].

\section{Patients' Global Evaluation}

A 7-point Likert scale ranging from "completely recovered", "much improved", "slightly improved", "slightly worsened", "much worsened" to "worse than ever" was used to evaluate participants' overall status [19].

\section{Statistical Analysis}

Data were tabulated using Microsoft EXCEL, and rigorous statistical analyses were performed using IBM SPSS Statistics Version 21.0 (IBM Corp., Armonk, NY).

\section{Internal Consistency}

Exploratory factor analysis was performed by the principal-component analysis [20]. Cronbach' a was used to assess the internal consistency of the scales. Generally, a Cronbach' $a>0.7$ is regarded as acceptable. All the completed baseline data of the Chinese IPSS and BII were included in the analysis [15].

\section{Reliability}

The intraclass correlation coefficients (ICCs) were used to evaluate the test-retest reliability of Chinese IPSS and BII. An ICC above 0.7 is considered to show good reliability. As the patients did not wish to stop 
their treatment, only the patients reported "no changed" on the patients' global evaluation were enrolled in the test-retest reliability evaluation.

\section{Validity}

In the absence of a gold standard for BPH, criterion validity could not be evaluated. To assess criterionrelated validity, we examined construct validity. We evaluated the relationships between the Chinese IPSS, BII, as well as VPSS, and SF-36 using the Pearson correlation coefficients $(r)$, where $r>0.40$ was considered satisfactory $(r>0.80$ is considered excellent, $0.61-0.80$ very good, $0.41-0.60$ good, $0.21-0.40$ fair, and 0-0.20 poor). All the completed baseline simplified Chinese IPSS, BII questionnaires with VPSS, as well as SF-36 scores were included in the analysis.

\section{Floor and Ceiling Effects}

Distributions of the items in simplified Chinese IPSS, and BII were checked for floor and ceiling effects, and more than $15 \%$ of respondents achieve the lowest or highest possible total score were considered with floor and ceiling effects. All the completed baseline simplified Chinese IPSS, and BII questionnaires were included in the analysis.

\section{Results}

\section{Testing of the Pre-final Version}

Thirty-one questionnaires that included suggestions about the pre-final Chinese IPSS, and BII were used. 13 were active, and 18 were retired. Participants had no problems completing the Chinese IPSS, and BII. Table 1 summarizes the patients' characteristics.

\section{Description of the Sample}

In total, 105 native Chinese-speaking male patients participated in the study, with a mean age of $65.5 \pm$ 12.8 years (Table 1). The duration of BPH was 3 to 96 months.

Workers (41/105) comprised the majority of patients, followed by farmers (19/105), policemen (11/105), and administrators $(5 / 105)$. For the test-retest reliability, all patients were asked to complete the questionnaires again after a 2-week interval. In total, 103 patients completed the second round of questionnaires, and data from 57 patients rated as "no change" on the global evaluation were analyzed for test-retest reliability (Table 1). Of the remaining 46 patients, 22 patients were rated as "slightly improved", 10 patients as "much improved", 2 patients as "completely recovered", 12 patients as "slightly worsened", and none as "much worsened" or "worse than ever". 


\section{Psychometric Properties}

\section{Participants and Missing Data}

The Chinese IPSS and BII showed satisfactory acceptability, with a completion time of $3.02 \pm 1.95$ minutes, and $2.57 \pm 1.39$ minutes, respectively. Participants had no problems completing the Chinese IPSS and BII.

\section{Internal Consistency}

Factor analysis of the simplified Chinese IPSS and BII were performed with the promax rotation, meanwhile, a three-factor structure was extracted in IPSS, and a two-factor structure in BII, respectively. Factor 1 of IPSS included items of incomplete emptying, frequency, intermittency, urgency, urinate hard, then Factor 2 contained items of weak stream, and nocturia, then QoL to Factor 3. Physical discomfort, and kept from usual activities were belong to Factor 1 of Bll, then worry and bothersome to Factor 2 of BII. Loadings of all items were presented in Table 2. Cronbach's a was 0.815 for the Chinese IPSS, 0.782 for IPSS-symptom, and 0.709 for the Chinese Bll, indicating high levels of internal consistency (Table 3).

\section{Reliability}

In total, 103 patients completed the second questionnaire round, at an interval of $9.31 \pm 3.79$ days; 57 patients rated "no change" were included in the test-retest analysis. The Chinese IPSS and BII scores were slightly lower in the retest rather than in the first test. The ICCs for the test-retest reliability were over 0.75 (IPSS, $r=0.836$ [0.786 to 0.886]; IPSS-symptom, $r=0.801$ [0.703 to 0.899]; IPSS-Qol, $r=0.794$ [0.680 to 0.908 ]; BII, $r=0.758$ [0.663 to 0.851$]$ ), indicating excellent test-retest reliability (Table 3).

\section{Validity}

We evaluated the relationships between the Chinese IPSS, BII, VPSS and SF-36 by the Pearson correlation coefficient. There were very good positive correlations between IPSS and BII ( $r=0.605)$, as well as VPSS $(r=0.634)$, very good positive correlations were also observed between IPSS-symptom and VPSSsymptom $(r=0.708)$, as well as between IPSS-Qol and VPSS-Qol $(r=0.725)$ (Table 4$)$.

There were very good negative correlations between IPSS-Qol and SF-36 physical functioning $(r=-0.621)$, and vitality $(r=-0.659)$. Then there were good negative correlations between IPSS-Qol and SF-36 rolephysical $(r=-0.533)$, general health $(r=-0.503)$, as well as vitality $(r=-0.427)$, then good negative correlation was also been observed between BII and SF-36 physical functioning $(r=-0.421)$ (Table 4). 


\section{Floor and Ceiling Effects}

There was no floor or ceiling effect of the simplified Chinese IPSS and BII.

\section{Discussion}

\section{Study summary}

This was the first simplified Chinese version of IPSS and BII developed based on the cross-cultural adaptation guidelines. In the study, we demonstrated that the simplified Chinese version of IPSS and BII were both valid, reliable and internally consistent instrument for assessing patients with BPH, which displayed no floor or ceiling effects. All items in the simplified Chinese version of IPSS and BII had the loadings of $>0.40$ in each factor. Furthermore, the Cronbach's a of 0.815 , and 0.709 indicated good internal consistency of these two scales. The test-retest results (ICC $=0.836$ for IPSS, ICC $=0.758$ for BII) confirmed excellent reliability. In addition, it was revealed that IPSS correlated well with BII, and VPSS, then IPSS-Qol correlated well with SF-36. Taken together, these results demonstrated that the simplified Chinese version of IPSS and BII was useful in evaluating Chinese patients with BPH in both clinical practice and research settings.

\section{The measurement properties compared with other versions}

The assessment of all the cross-cultural IPSS and Bll adaptation of other languages was conducted for the measurement properties [11-14, 21-23]. The summary of the measurement properties regarding the original and cross-cultural IPSS and BII adaptations were shown in Table 5.

Four adaptations of IPSS performed factor analysis, while, the results were different $[11,12,21]$. The consensus was that the IPSS-symptom consisted of two factors, then the specific items were different. Compared with other adaptations, our factor analysis result was in accordance with the Japanese IPSS adaptation [21]. All the cross-cultural IPSS adaptation conducted the test of internal consistency and the most common results were acceptable, except Malay-Malaysian IPSS adaptation, as only 40 participants were enrolled, this result might not be accurate enough in Malay-Malaysian IPSS adaptation [18]. The test-retest reliability was tested in all of the adaptations, only the IPSS-Qol of Spanish adaptation did not get a good result $(I C C=0.59)$. Only three adaptations conducted construct validity, there were very good positive correlations between IPSS and BII $(r=0.605)$, as well as VPSS $(r=0.634)$ in simplified Chinese IPSS, then good positive correlations between IPSS and International Consultation on Incontinence Questionnaire-Urinary Incontinence Short Form (ICIQ-UI SF; $r=0.47$ ), and IPSS-Qol and Incontinence impact questionnaire (IIQ-7; $r=0.46)$ in Traditional Chinese-Hong Kong adaptation, and fair and poor correlation were between IPSS and EuroQol Five-Dimensional Questionnaire (EQ-5D; $r=0.07-0.36$ ) in Spanish adaptation $[12,23]$. 
The BII was only translated into Japanese previously, there was only one factor in Japanese adaptation, then two factors were found in simplified Chinese adaptation, one focused on physical health, and another on focused on mental health [21]. Both these two adaptations conducted internal consistency and test-retest reliability, which indicated that both Japanese and simplified Chinese Bll showed good internal consistency and test-retest reliability.

\section{Limitations}

Several limitations of our study are worth noting. One limitation is the lack of a responsiveness and agreement study. We recommend future prospective studies to complete the assessment of the psychometric properties of this scale. The sample size for cross-cultural adaptation was sufficient but not adequate when the patients were grouped based on the severity of BPH.

\section{Conclusion}

The simplified Chinese version of the IPSS and Bll showed high internal consistency, sufficient test-retest reliability, and high construct validity, which meant that both these two simplified Chinese adaptations were reliable and valid for use in mainland Chinese patients with LUTS due to BPH. Future studies should examine additional measurement properties of the Chinese IPSS and BII for patients with LUTS due to $\mathrm{BPH}$ in the mainland Chinese population.

\section{Abbreviations}

IPSS, international prostate symptom score; Bll, benign prostatic hyperplasia impact index; BPH, benign prostatic hyperplasia; ICC, intraclass correlation coefficient; VPSS, visual prostate symptom score; SF-36, 36 items Short Form Health Survey; LUTS, lower urinary tract symptoms; QoL, quality of life; AUA, American Urological Association; AUA-SI, AUA symptom index; PGE, Patients' Global Evaluation; ICIQ-UI SF, International Consultation on Incontinence Questionnaire-Urinary Incontinence Short Form; IIQ7, Incontinence impact questionnaire; EQ-5D, EuroQol Five-Dimensional Questionnaire.

\section{Declarations}

\section{Data Availability Statement}

The datasets used and/or analysed during the current study are available from the corresponding author on reasonable request.

\section{Consent for publication}




\section{Author Contributions}

The study was conceived by RLD and YP. RLD and YP organized the translation and revision, RLD, JMM, $\mathrm{CY}, \mathrm{ZQ}, \mathrm{XHH}, \mathrm{WJZ}$, and GCQ, enrolled patients. RLD and YP wrote the manuscript.

\section{Funding}

This work was supported by the Leading talents plan of TCM of Shanghai (ZY(2018-2020)-RCPY-1017).

\section{Conflict of Interest}

The authors declare that they have no competing interests.

\section{References}

1. Devlin CM, Simms MS, Maitland NJ: Benign prostatic hyperplasia - what do we know? BJU Int2021, 127:389-399.

2. Lepor H: Alpha-blockers for the Treatment of Benign Prostatic Hyperplasia. Urol Clin North Am2016, 43:311-323.

3. Langan RC: Benign Prostatic Hyperplasia. Prim Care2019, 46:223-232.

4. Park S, Ryu JM, Lee M: Quality of Life in Older Adults with Benign Prostatic Hyperplasia. 2020, 8.

5. Barry MJ, Fowler FJ, Jr., O'Leary MP, Bruskewitz RC, Holtgrewe HL, Mebust WK, Cockett AT: The American Urological Association symptom index for benign prostatic hyperplasia. The Measurement Committee of the American Urological Association. J Uro/1992, 148:1549-1557; discussion 1564.

6. Cockett ATK, Khoury S, Y A: The 2nd International Consultation on BPH. Proceedings Jersey, Channel Islands: Scientific Communication International, Ltd1993.

7. Barry MJ, Fowler FJ, Jr., O'Leary MP, Bruskewitz RC, Holtgrewe HL, Mebust WK: Measuring diseasespecific health status in men with benign prostatic hyperplasia. Measurement Committee of The American Urological Association. Med Care1995, 33:As145-155.

8. Boyle P, Robertson C, Mazzetta C, Keech M, Hobbs FD, Fourcade R, Kiemeney L, Lee C: The prevalence of lower urinary tract symptoms in men and women in four centres. The UrEpik study. BJU Int2003, 92:409-414.

9. Ponholzer A, Temml C, Wehrberger C, Marszalek M, Madersbacher S: The association between vascular risk factors and lower urinary tract symptoms in both sexes. Eur Uro/2006, 50:581-586.

10. Okamura K, Nojiri Y, Osuga Y, Tange C: Psychometric analysis of international prostate symptom score for female lower urinary tract symptoms. Urology2009, 73:1199-1202. 
11. Arshad Z, Zaidi SZ, Jamshaid A: Development, validity and reliability of an URDU version of the International Prostate Symptom Score. J Pak Med Assoc2018, 68:200-202.

12. Choi EP, Lam CL, Chin WY: Validation of the International Prostate Symptom Score in Chinese males and females with lower urinary tract symptoms. Health Qual Life Outcomes2014, 12:1.

13. Hammad FT, Kaya MA: Development and validation of an Arabic version of the International Prostate Symptom Score. BJU Int2010, 105:1434-1438.

14. Quek KF, Chua CB, Razack AH, Low WY, Loh CS: Construction of the Mandarin version of the International Prostate Symptom Score inventory in assessing lower urinary tract symptoms in a Malaysian population. Int J Uro/2005, 12:39-45.

15. Terwee CB, Bot SD, de Boer MR, van der Windt DA, Knol DL, Dekker J, Bouter LM, de Vet HC: Quality criteria were proposed for measurement properties of health status questionnaires. $J$ Clin Epidemio/2007, 60:34-42.

16. van der Walt CL, Heyns CF, Groeneveld AE, Edlin RS, van Vuuren SP: Prospective comparison of a new visual prostate symptom score versus the international prostate symptom score in men with lower urinary tract symptoms. Urology2011, 78:17-20.

17. Brazier JE, Harper R, Jones NM, O'Cathain A, Thomas KJ, Usherwood T, Westlake L: Validating the SF-36 health survey questionnaire: new outcome measure for primary care. Bmj1992, 305:160-164.

18. Li L, Wang HM, Shen Y: Chinese SF-36 Health Survey: translation, cultural adaptation, validation, and normalisation. J Epidemiol Community Health2003, 57:259-263.

19. Fischer D, Stewart AL, Bloch DA, Lorig K, Laurent D, Holman H: Capturing the patient's view of change as a clinical outcome measure. Jama1999, 282:1157-1162.

20. Pickering PM, Osmotherly PG, Attia JR, McElduff P: An examination of outcome measures for pain and dysfunction in the cervical spine: a factor analysis. Spine (Phila Pa 1976)2011, 36:581-588.

21. Homma Y, Tsukamoto T, Yasuda K, Ozono S, Yoshida M, Yamaguchi T: [Evaluation of psychometric properties of Japanese version of international prostate symptom score and BPH impact index]. Nihon Hinyokika Gakkai Zasshi2003, 94:560-569.

22. Quek KF, Low WY, Razack AH, Sin Loh C, Chua CB: Reliability and validity of the Malay version of the International Prostate Symptom Score in the Malaysian population. J Uro/2002, 167:1359-1362.

23. Badía X, García-Losa M, Dal-Ré R, Carballido J, Serra M: Validation of a harmonized Spanish version of the IPSS: evidence of equivalence with the original American scale. International Prostate Symptom Score. Urology1998, 52:614-620.

\section{Tables}

Table 1

Demographic characteristics of participants in the three study stages 


\begin{tabular}{|c|c|c|c|}
\hline Characteristic & $\begin{array}{l}\text { Pre-final Group } \\
(n=31)\end{array}$ & $\begin{array}{l}\text { Validity Group } \\
(n=105)\end{array}$ & $\begin{array}{l}\text { Reliability Group } \\
(n=57)\end{array}$ \\
\hline Age, years & $64.1 \pm 10.4$ & $65.5 \pm 12.8$ & $64.7 \pm 11.9$ \\
\hline Disease duration, weeks & $33.78 \pm 60.96$ & $34.05 \pm 67.01$ & $32.93 \pm 62.44$ \\
\hline Occupation, active/retired & $13 / 18$ & $49 / 56$ & $23 / 34$ \\
\hline IPSS & $19.05 \pm 5.38$ & $18.74 \pm 5.09$ & $18.01 \pm 4.21$ \\
\hline IPSS-sympton & $15.01 \pm 6.25$ & $14.97 \pm 6.06$ & $14.15 \pm 5.93$ \\
\hline IPSS-Qol & $4.05 \pm 2.69$ & $4.12 \pm 2.08$ & $4.15 \pm 2.06$ \\
\hline BII & / & $4.83 \pm 1.24$ & $4.39 \pm 1.15$ \\
\hline VPSS & / & $15.56 \pm 5.13$ & $15.04 \pm 5.39$ \\
\hline VPSS-sympton & / & $12.11 \pm 5.88$ & $12.05 \pm 5.41$ \\
\hline VPSS-QoL & / & $3.44 \pm 1.09$ & $3.15 \pm 1.12$ \\
\hline \multicolumn{4}{|l|}{ SF-36 } \\
\hline Physical functioning & / & $60.34 \pm 22.51$ & $62.33 \pm 21.65$ \\
\hline Role-physical & / & $19.98 \pm 25.31$ & $24.01 \pm 20.45$ \\
\hline Bodily pain & / & $45.33 \pm 16.45$ & $49.50 \pm 15.91$ \\
\hline General health & / & $51.32 \pm 17.27$ & $51.30 \pm 16.86$ \\
\hline Vitality & / & $53.70 \pm 17.25$ & $56.82 \pm 16.94$ \\
\hline Social functioning & / & $78.66 \pm 26.36$ & $81.79 \pm 21.05$ \\
\hline Role-emotional & / & $35.96 \pm 41.52$ & $36.03 \pm 36.06$ \\
\hline Mental health & / & $60.36 \pm 17.88$ & $61.49 \pm 15.68$ \\
\hline
\end{tabular}

Table 2

Factor analyses for the simplified Chinese IPSS and BHI items with promax-rotated factor loadings 


\begin{tabular}{|c|c|c|c|}
\hline \multirow[t]{2}{*}{ Item } & \multicolumn{3}{|c|}{ Principal Component Coefficients $\geq 0.4$} \\
\hline & Factor 1 & Factor 2 & Factor 3 \\
\hline \multicolumn{4}{|l|}{ IPSS } \\
\hline Incomplete emptying & 0.543 & & \\
\hline Frequency & 0.426 & & \\
\hline Intermittency & 0.610 & & \\
\hline Urgency & 0.594 & & \\
\hline Weak stream & & 0.435 & \\
\hline Urinate hard & 0.602 & & \\
\hline Nocturia & & 0.576 & \\
\hline Quality of life & & & 0.540 \\
\hline \multicolumn{4}{|l|}{$\mathrm{BHI}$} \\
\hline Physical discomfort & 0.737 & & \\
\hline Worry & & 0.536 & \\
\hline Bothersome & & 0.609 & \\
\hline Kept from usual activities & 0.650 & & \\
\hline
\end{tabular}

Table 3

Internal consistency and test-retest reliability of the simplified Chinese IPSS and BHI

\begin{tabular}{|llll|}
\hline Scales & Number of items & Cronbach's a $(\mathbf{n = 1 0 5 )}$ & $\begin{array}{l}\text { ICC } \\
(\mathbf{n}=57)\end{array}$ \\
\hline IPSS & 7 & 0.815 & $0.836[0.786$ to 0.886$]$ \\
\hline IPSS-symptom & 6 & 0.782 & $0.801[0.703$ to 0.899$]$ \\
\hline IPSS-QoL & 1 & $/$ & $0.794[0.680$ to 0.908$]$ \\
\hline BII & 4 & 0.709 & $0.758[0.663$ to 0.851$]$ \\
\hline IPSS, international prostate symptom score; BHI, benign prostatic hyperplasia impact index. \\
\hline
\end{tabular}


Table 4

Pearson correlation coefficient (r) of the simplified Chinese IPSS and BII with VPSS, and SF-36

\begin{tabular}{|lllll|}
\hline Score & IPSS & IPSS-symptom & IPSS-QoL & BII \\
\hline IPSS & $/$ & $0.840^{*}$ & $0.731^{* *}$ & $0.605^{*}$ \\
\hline IPSS-symptom & $\mathbf{0 . 8 4 0 ^ { * }}$ & $/$ & 0.392 & $\mathbf{0 . 5 3 4}$ \\
\hline IPSS-QoL & $\mathbf{0 . 7 3 1 ^ { * }}$ & 0.392 & $/$ & 0.319 \\
\hline BII & $\mathbf{0 . 6 0 5 ^ { * }}$ & $\mathbf{0 . 5 3 4}$ & 0.319 & $/$ \\
\hline VPSS & $\mathbf{0 . 6 3 4 ^ { * }}$ & $\mathbf{0 . 6 2 8 ^ { * }}$ & $\mathbf{0 . 4 5 2}$ & $\mathbf{0 . 6 9 2 ^ { * }}$ \\
\hline VPSS-symptom & $\mathbf{0 . 6 9 3 ^ { * }}$ & $\mathbf{0 . 7 0 8 ^ { * }}$ & 0.308 & $\mathbf{0 . 4 1 8 ^ { * }}$ \\
\hline VPSS-Qol & 0.306 & 0.291 & $\mathbf{0 . 7 2 5 ^ { * }}$ & 0.393 \\
\hline SF-36 & & & $-0.621^{*}$ & $-0.421^{*}$ \\
\hline Physical functioning & $-0.329^{*}$ & $-0.227^{*}$ & $-0.533^{*}$ & -0.304 \\
\hline Role-physical & -0.267 & -0.196 & -0.427 & $-0.395^{*}$ \\
\hline Bodily pain & -0.391 & $-0.205^{*}$ & $-0.503^{*}$ & $-0.293^{*}$ \\
\hline General health & $-0.284^{*}$ & -0.213 & $-0.659^{*}$ & -0.182 \\
\hline Vitality & -0.124 & $-0.390^{*}$ & -0.336 & $-0.219^{*}$ \\
\hline Social functioning & $-0.308^{*}$ & $-0.285^{*}$ & -0.347 & -0.287 \\
\hline Role-emotional & $-0.315^{*}$ & -0.114 & $-0.330^{*}$ \\
\hline Mental health & -0.226 & -0.201 & & \\
\hline IPSS, international prostate symptom score; BHI, benign prostatic hyperplasia impact \\
Nindex; VPSS, Visual Prostate Symptom Score; SF-36, Short Form Health Survey.
\end{tabular}

Table 5

The summary of the measurement properties of cross-cultural IPSS, and BII adaptations. 


\begin{tabular}{|c|c|c|c|c|c|}
\hline Score & Sample size & Factor analysis & $\begin{array}{l}\text { Internal } \\
\text { consistency }\end{array}$ & $\begin{array}{l}\text { Test-retest } \\
\text { reliability }\end{array}$ & $\begin{array}{l}\text { Construct } \\
\text { validity }\end{array}$ \\
\hline \multicolumn{6}{|l|}{ IPSS } \\
\hline $\begin{array}{l}\text { Arabic- } \\
\text { United } \\
\text { Arab } \\
\text { Emirates }\end{array}$ & 76 & / & $\begin{array}{l}\text { Cronbach's } \\
\text { a } \\
\text { IPSS- } \\
\text { symptom } \\
0.85\end{array}$ & $\begin{array}{l}\text { ICC } \\
\text { IPSS-symptom } \\
0.88 \\
\text { IPSS-QoL } 0.71\end{array}$ & I \\
\hline Japanese & $\begin{array}{l}103 \text { with } \\
\text { BPH and } 23 \\
\text { asymptomatic } \\
\text { men }\end{array}$ & $\begin{array}{l}\text { Factor loading: } \\
\text { Factor } 1 \\
\text { Item } 10.39 \text { Item } 2 \\
0.38 \text { Item } 30.39 \\
\text { Item } 50.36 \text { Item } \\
60.41 \\
\text { Factor } 2 \\
\text { Item } 40.45 \text { Item } 7 \\
0.36\end{array}$ & $\begin{array}{l}\text { Cronbach's } \\
\text { a } \\
\text { IPSS- } \\
\text { symptom } \\
0.83\end{array}$ & $\begin{array}{l}\text { ICC } \\
\text { IPSS-symptom } \\
0.82 \\
\text { IPSS-QoL } 0.71\end{array}$ & / \\
\hline $\begin{array}{l}\text { Malay- } \\
\text { Malaysian }\end{array}$ & $\begin{array}{l}20 \text { men with } \\
\text { LUTS, and } 20 \\
\text { controls }\end{array}$ & l & $\begin{array}{l}\text { Cronbach's } \\
\text { a } \\
\text { IPSS- } \\
\text { symptom } \\
0.68 \\
\\
\text { IPSS-Qol } \\
0.79\end{array}$ & $\begin{array}{l}\text { ICC } \\
\text { IPSS-symptom } \\
0.70 \\
\text { IPSS-QoL } 0.79\end{array}$ & / \\
\hline $\begin{array}{l}\text { Mandarin- } \\
\text { Malaysian }\end{array}$ & $\begin{array}{l}39 \text { with } \mathrm{BPH} \\
\text { and } 29 \text { control }\end{array}$ & / & $\begin{array}{l}\text { Cronbach's } \\
\text { a } \\
\text { IPSS- } \\
\text { symptom } \\
\text { for BPH } \\
0.96-0.98 \\
\text { IPSS- } \\
\text { symptom } \\
\text { for control } \\
0.86-0.98\end{array}$ & $\begin{array}{l}\text { ICC } \\
\text { IPSS-symptom } \\
\text { for BPH 0.93- } \\
0.99 \\
\text { IPSS-symptom } \\
\text { for control } \\
0.97-0.99\end{array}$ & / \\
\hline $\begin{array}{l}\text { Simplified } \\
\text { Chinese }\end{array}$ & 105 & $\begin{array}{l}\text { Factor loading: } \\
\text { Factor } 1 \\
\text { Item } 10.543 \\
\text { Item } 20.426 \\
\text { Item } 30.610 \\
\text { Item } 40.594\end{array}$ & $\begin{array}{l}\text { Cronbach's } \\
\text { a } \\
\text { IPSS } 0.836 \\
\text { IPSS- } \\
\text { symptom } \\
0.782\end{array}$ & $\begin{array}{l}\text { ICC } \\
\text { IPSS } 0.836 \\
\text { IPSS- } \\
\text { symptom } 0.801 \\
\text { IPSS-QoL } 0.794\end{array}$ & $\begin{array}{l}\text { Pearson's } \\
\text { correlations } \\
\text { BII } 0.605 \\
\text { VPSS } \\
0.634\end{array}$ \\
\hline
\end{tabular}


Item 60.602

Factor 2

Item 50.435 Item

70.576

Factor 3

Item 80.540

$\begin{array}{ll}\text { Spanish } & 59 \text { with BPH / } \\ & \text { and } 68 \\ & \text { control }\end{array}$

Urdu-

267

Pakistanis

Traditional 233

Chinese-

Hong

Kong

\section{Cronbach's ICC \\ a}

IPSS-

symptom

0.79
VPSS-

symptom

0.693

VPSS-QoL

0.306
IPSS-symptom

0.87

IPSS-QoL 0.59

\section{Pearson's} correlations

EQ-5D 0.070.36

EQ-5D VSA $-0.29$

PGWBI

dimension

0.14-0.41
Factor loading:

Factor 1

Item 10.517 Item

30.877

Item 50.789 Item

60.848

Factor 2

Item 20.762 Item

40.776

Item 70.746
Cronbach's ICC

\section{a}

IPSS 0.72
IPSS-symptom

0.92

\section{I}

IPSS-QoL 0.75

\section{Corrected item-} total correlation

Item 10.58 Item 2 0.38

Item 30.57 Item 4 0.30

Item 50.57 Item 6 0.42

Item 70.20

\section{Cronbach's ICC \\ a \\ Pearson's correlations}

IPSS-symptom

0.80

IPSS-QoL 0.70
IPSS-

symptom

ICIQ-UI SF

0.47

IPSS-QoL

IIQ-7 0.46

SF 12 PCS

$-0.17$

SF 12 MCS

$-0.21$ 
BII

\begin{tabular}{|c|c|c|c|c|c|}
\hline \multirow[t]{4}{*}{ Japanese } & 103 with & Factor loading: & \multirow{4}{*}{$\begin{array}{l}\text { Cronbach's } \\
\mathbf{a} \\
0.90\end{array}$} & ICC & / \\
\hline & \multirow{3}{*}{$\begin{array}{l}\mathrm{BPH} \text { and } 23 \\
\text { asymptomatic } \\
\text { men }\end{array}$} & Factor 1 & & \multirow[t]{3}{*}{0.67} & \\
\hline & & $\begin{array}{l}\text { Item } 10.51 \text { Item } \\
20.48\end{array}$ & & & \\
\hline & & $\begin{array}{l}\text { Item } 30.51 \text { Item } \\
40.50\end{array}$ & & & \\
\hline \multirow[t]{6}{*}{$\begin{array}{l}\text { Simplified } \\
\text { Chinese }\end{array}$} & \multirow[t]{6}{*}{105} & Factor loading: & \multirow[t]{2}{*}{$\begin{array}{l}\text { Cronbach's } \\
\text { a }\end{array}$} & \multirow{2}{*}{$\begin{array}{l}\text { ICC } \\
0.758\end{array}$} & $\begin{array}{l}\text { Pearson's } \\
\text { correlations }\end{array}$ \\
\hline & & Factor 1 & & & BII 0.605 \\
\hline & & $\begin{array}{l}\text { Item } 10.737 \\
\text { Item } 40.650\end{array}$ & & & VPSS \\
\hline & & Factor 2 & & & \\
\hline & & $\begin{array}{l}\text { Item } 20.536 \\
\text { Item } 30.609\end{array}$ & & & $\begin{array}{l}\text { symptom } \\
0.693\end{array}$ \\
\hline & & & & & $\begin{array}{l}\text { VPSS-QoL } \\
0.306\end{array}$ \\
\hline
\end{tabular}

IPSS, international prostate symptom score; BHI, benign prostatic hyperplasia impact index; ICC, intraclass correlation coefficients; BPH, benign prostatic hyperplasia, LUTS, lower urinary tract symptoms; Qol, quality of life; VPSS, Visual Prostate Symptom Score; VSA, visual analogue scale; EQ-5D, EuroQol Five-Dimensional Questionnaire; PGWBI, Psychological General Well-Being Index; ICIQ-UI SF, International Consultation on Incontinence Questionnaire-Urinary Incontinence Short Form; IIQ-7, Incontinence impact questionnaire; SF-12, 12-Item Short Form Health Survey.

Notes: ${ }^{*}$ Correlation is significant at the 0.05 level (2-tailed). 